\title{
Functionality of Short Chain Amylose-Lipid Complexes in Starch-Water Systems and Their Impact on in Vitro Starch Degradation
}

\author{
Joke A. Putseys, ${ }^{*}, \dagger$ Liesbeth J. Derde, ${ }^{\dagger}$ Lieve Lamberts, ${ }^{\dagger}$ Elin Östman, ${ }^{*}$ \\ IngER M. BJÖrCK, ${ }^{\star}$ AND JAN A. Delcour ${ }^{\dagger}$
}

\begin{abstract}
${ }^{\dagger}$ Laboratory of Food Chemistry and Biochemistry, and Leuven Food Science and Nutrition Research Centre (LFoRCe), Katholieke Universiteit Leuven, Kasteelpark Arenberg 20, B-3001 Heverlee, Belgium and Division of Applied Nutrition and Food Chemistry, Lund University, P.O. Box 124, SE 22100 Lund, Sweden
\end{abstract}

\begin{abstract}
Monodisperse short-chain amorphous or semicrystalline amylose-glycerol monostearate (GMS) complexes, or, as a reference, pure GMS, were added to starch dispersions which were gelatinized and allowed to cool. The largest impacts on rheological properties were observed when GMS or amorphous GMS complexes were added. The controlled release of the short amylose chains of the latter induced double helix and, thus, network formation, resulting in higher viscosity readings. As the lipid is set free after starch gelatinization, it is assumed that it complexes with amylose leached outside the granule, whereas additional pure GMS can probably to a greater extent complex inside the granule. Semicrystalline complexes could be considered as inert mass in the starch systems as their melting temperature exceeded the temperature reached during the experiment. The additives also impacted starch's sensitivity to enzymatic degradation. GMS addition reduced the resistant starch (RS) content of the gels and increased their hydrolysis index (HI). Added amorphous or semicrystalline complexes, on the other hand, yielded gels with a higher RS content and a lower HI. Addition of amylose-lipid complexes to starch suspensions impacts starch gel characteristics and decreases its digestion rate, possibly by releasing short amylose chains in a controlled way that then participate in amylose crystallization and, hence, RS formation.
\end{abstract}

KEYWORDS: amylose-lipid complex; starch; viscosity; resistant starch

\section{INTRODUCTION}

Emulsifiers can be used in starch-containing systems to improve processing and/or quality of final products $(1)$. They can exert effects in various ways. They either interfere with protein networks $(2,3)$, increase starch granule rigidity, change the water distribution, and/or influence the swelling of starch granules, hence impacting viscosity $(2,4-7)$. They can form a layer surrounding the granule consisting of uncomplexed emulsifiers (8). However, as a sequel to gelatinization of starch, complexation of emulsifiers containing fatty acid chains and amylose can occur (9). Such in situ amylose-lipid complexation postpones starch swelling as well, by delaying water transport into the granules and/or preventing further amylose solubilization $(4,10,11)$. Alternatively, amylose-lipid formation may occur inside the granule after migration of small emulsifiers into the granule, hence inhibiting further leaching of amylose $(12,13)$.

Another consequence of amylose-lipid complexation is the impediment to amylose-amylose double helix formation and crystallization during cooling of a heated starch sample (2). This reduces resistant starch (RS) formation $(14,15)$. RS is that part of

*Corresponding author: tel +32 (0)16 321634, fax +32 (0)16 321997, e-mail: joke.putseys@ biw.kuleuven.be. starch that escapes digestion in the small intestine of healthy individuals. However, it can be fermented in the large intestine, and, as such, can be considered as belonging to the dietary fiber fraction $(16,17)$. RS has been divided into four categories $(18)$ : physically inaccessible starch (RS1), natural granular starch (RS2), retrograded starch (RS3), and chemically modified starch (RS4) (19). In general, RS3, that is, predominantly crystalline amylose, is the major contributor to the total RS fraction of heated and cooled starch-containing foods (20).

We envisaged two ways in which amylose-lipid complexation is relevant in this context. First, in situ amylose-lipid complexation can reduce the level of RS in a starch sample, and increase the starch hydrolysis rate (15). Thus, by interfering with amylose crystallization, digestibility of the sample is impacted. Second, amylose-lipid complexes are degraded more slowly than noncomplexed amylose $(21,22)$.

Amylose-inclusion complexes as such have only sporadically been used as additives in starch-containing systems. Gudmundsson (23) studied the impact on retrogradation of the addition of an amylose-cetyltrimethylammonium bromide complex to different starches which were then subjected to various hydrothermal treatments. He concluded that surfactants exert the greatest effect when added in their noncomplexed form. Gelders et al. (24) 
used amylose-lipid complexes as additives to starch suspensions and postulated a possible role as controlled release agents for the complexed ligand. However, these authors did not remove the uncomplexed lipids from their samples. This may have impacted the gelatinization and pasting of the starch suspension.

In this study, we aimed at unraveling the influence of amyloselipid complexes on starch enzyme degradability. We produced amylose-lipid complexes semienzymically with shorter amylose chains and more monodisperse (25) than the rather polydisperse amylose-lipid complexes synthesized "classically" by complexing amylose with lipid $(26-28)$.

This was, first of all, approached by using monodisperse complexes as additives in starch dispersions and investigating their functionality "as such". The influence of these additives on rheological properties and, in a final phase, on the gel RS content and hydrolysis index (HI), that is, the area under the starch hydrolysis curve as a function of time, as a percentage of that of the hydrolysis curve of a reference (29), was studied.

\section{MATERIALS AND METHODS}

Materials. All chemicals and reagents, including glycerol monostearate (GMS), $\alpha$-D-glucose-1-phosphate disodium salt tetrahydrate (glc1-P), oyster glycogen, pepsin, and pancreatin were at least analytical grade and from Sigma-Aldrich (Bornem, Belgium) unless specified otherwise. The pancreatin used had three times the activity specified in United States Pharmacopeia (USP), that is, at least 75 USP units of amylase (and protease) and at least 6 USP units of lipase per mg of product.

Pseudomonas sp. isoamylase and the glucose oxidase - peroxidase reagent (GOPOD) assay kit were from Megazyme (Bray, Ireland). Potato starch amylose and commercial wheat starch, with an amylose content of $25 \%$ and a lipid content of about $1.0 \%$, were from Syral (Aalst, Belgium). The thermostable $\alpha$-amylase Termamyl $120 \mathrm{~L}$ was from Novozymes (Bagsvaerd, Denmark). Unless otherwise indicated, all enzyme units (EU) listed were those as defined by the respective suppliers.

Methods. Potato Phosphorylase Extraction. Potato phosphorylase was extracted from locally purchased Nicola potatoes (Solanum tuberosum cv. Nicola), as described by Roger et al. (30), with minor adaptations made by Gelders et al. (25). The enzyme activity of the suspension was determined by quantifying liberated phosphate with the method of Saheki et al. (31). One enzyme unit (EU) is the amount of enzyme ( $\mathrm{mL}$ suspension) releasing $1 \mu \mathrm{mol}$ of phosphate per min from glc-1-P at $37^{\circ} \mathrm{C}$ and $\mathrm{pH} 6.2$ ( $0.10 \mathrm{M}$ sodium citrate buffer).

Synthesis of the Primer by Debranching Glycogen. Oyster glycogen $(5.0 \mathrm{~g})$ was dispersed in $250 \mathrm{~mL}$ of sodium acetate buffer $(0.05 \mathrm{~N}, \mathrm{pH} 3.8)$, $25 \mathrm{EU}$ isoamylase was added, and the mixture was incubated at $37^{\circ} \mathrm{C}$ for $48 \mathrm{~h}$. The enzyme was inactivated by heat treatment $\left(10 \mathrm{~min}, 100^{\circ} \mathrm{C}\right)$. The average degree of polymerization (DP) of the primer was calculated as the ratio of the total glucose content (determined according to the phenolsulfuric acid method (32)) to the total reducing sugar content (determined according to the Somogyi-Nelson method $(33,34))$.

\section{Formation of Amylose-Lipid Complexes}

Semienzymic Synthesis. Large quantities of monodisperse amylose-lipid complexes were synthesized and recovered as described earlier (25), with debranched glycogen as primer, GMS as lipid, glc-1-P as substrate, and potato phosphorylase as the catalyst. The precipitated amylose-lipid complexes were removed from the reaction medium by centrifugation, washed, and again recovered by centrifugation. This resulted in semienzymically synthesized amorphous type I amylose-lipid complexes [further referred to as semienzymically synthesized (SES) "SESAMLCI"]. Part of this pellet was further subjected to a heat treatment $\left(50 \mathrm{~min}, 110^{\circ} \mathrm{C}\right)$. Afterward, the sample was left to cool slowly, resulting in semicrystalline type II amylose-lipid complexes (further referred to as "SES-AMLCII"). The amylose-lipid complexes, in both cases, contain glucose chains with an average degree of polymerization (DP) of around 100. Finally, the complexes were lyophilized.

Classical Formation. Amylose-lipid complexes were also synthesized based on Galloway et al. (27). For this solution-grown method, $4.0 \mathrm{~g}$ of amylose (from potato starch) was dissolved in $25.0 \mathrm{~mL}$ of hot dimethyl sulfoxide. The solution was then diluted with $375.0 \mathrm{~mL}$ of boiling water, kept at $100^{\circ} \mathrm{C}$ for $30 \mathrm{~min}$, and then equilibrated at either 60 or $90^{\circ} \mathrm{C}$. GMS $(0.80 \mathrm{~g})$ was dissolved in $20 \mathrm{~mL}$ of hot ethanol $(96 \%)$ and added dropwise to the solutions under continuous stirring. The mixture was incubated for $240 \mathrm{~min}$ (with stirring every $30 \mathrm{~min}$ ). It was then left to cool slowly overnight. The formed complexes were recovered by centrifugation $\left(10000 \mathrm{~g}, 30 \mathrm{~min}, 6^{\circ} \mathrm{C}\right)$. The pellet was washed with water, centrifuged $\left(10000 \mathrm{~g}, 15 \mathrm{~min}, 6^{\circ} \mathrm{C}\right)$, and freeze-dried. These classically synthesized complexes are further referred to as amorphous classically synthesized (CS) "CS-AMLC60" and semicrystalline "CS-AMLC90", the codes 60 and 90 referring to the respective temperatures (in ${ }^{\circ} \mathrm{C}$ ). In this case, the DP of the amylose-lipid complexes equaled that of the amylose starting material with a DP of around 220.

Removal of Excess Lipids. Uncomplexed lipids were removed from the complexes by suspending the latter in chloroform $\left(60 \mathrm{~mL}\right.$ of $\mathrm{CHCl}_{3} / \mathrm{g}$ of complex) at room temperature. After $30 \mathrm{~min}$, the suspension was filtered using a sintered glass filter (porosity 4). The defatted complexes were airdried overnight.

Differential Scanning Calorimetry. Differential scanning calorimetry (DSC Q1000, TA Instruments, New Castle, DE, USA), was used to determine the transition temperatures and enthalpies of the defatted complexes. The different amylose-lipid complexes (1.5-4.0 mg of dry matter, $\mathrm{dm}$ ) were accurately weighed into coated aluminum pans (PerkinElmer, Waltham, MA, USA). Water was added to obtain a final moisture content of $75.0 \%$, and the pans were hermetically sealed. The sample pans and an empty reference pan were equilibrated at $0{ }^{\circ} \mathrm{C}$ and heated to $140{ }^{\circ} \mathrm{C}$ at a heating rate of $4{ }^{\circ} \mathrm{C} / \mathrm{min}$. Onset $\left(T_{\mathrm{o}}\right)$, peak $\left(T_{\mathrm{p}}\right)$, and conclusion temperatures $\left(T_{\mathrm{c}}\right)$, and temperature range $\left(T_{\mathrm{c}}-T_{\mathrm{o}}\right)$ and enthalpy $(\Delta H)$ of the synthesized defatted amylose-lipid complexes were determined using Universal Analysis 2000 software (TA Instruments). Results are averages of at least three measurements.

SES-AMLCI had a $T_{\mathrm{p}}$ of $98.2( \pm 0.3)^{\circ} \mathrm{C}$, with $T_{\mathrm{c}}-T_{\mathrm{o}} 29.1( \pm 0.4)^{\circ} \mathrm{C}$, and $\Delta H$ of $23.1( \pm 0.4) \mathrm{J} / \mathrm{g}$ defatted amylose-lipid complex. For SESAMLCII, $T_{\mathrm{p}}$ was $118.3( \pm 0.3){ }^{\circ} \mathrm{C}$, with $T_{\mathrm{c}}-T_{\mathrm{o}} 21.6( \pm 1.0){ }^{\circ} \mathrm{C}$, and $\Delta H 23.9( \pm 1.3) \mathrm{J} / \mathrm{g}$ defatted amylose-lipid complex. The classically synthesized CS-AMLC60 had a peak dissociation temperature of 101.8 $( \pm 0.2)^{\circ} \mathrm{C}$, with $T_{\mathrm{c}}-T_{\mathrm{o}} 15.8( \pm 1.3)^{\circ} \mathrm{C}$, and $\Delta H 23.8( \pm 0.3) \mathrm{J} / \mathrm{g}$ defatted amylose-lipid complex. CS-AMLC90, on the other hand, had a higher $T_{\mathrm{p}}$ $\left[118.8( \pm 0.5){ }^{\circ} \mathrm{C}\right]$, a $T_{\mathrm{c}}-T_{\mathrm{o}} 19.1( \pm 1.5){ }^{\circ} \mathrm{C}$, and $\Delta H$ of $26.9( \pm 2.4) \mathrm{J} / \mathrm{g}$ defatted amylose-lipid complex.

Rapid Visco Analyzer (RVA). Starch rheological properties were studied using a RVA (model RVA-4D; Newport Scientific, Sydney, Australia). Starch without and with addition of GMS $(0.1-1.0 \% \mathrm{w} / \mathrm{w}$, calculated on starch $\mathrm{dm})$, defatted SES-AMLCI $(0.5-5.0 \% \mathrm{w} / \mathrm{w})$ or defatted SES-AMLCII $(0.5-5.0 \% \mathrm{w} / \mathrm{w})$ was supplemented with deionized water (up to $8.0 \% \mathrm{dm}$ starch) and mixed in a RVA cup. All additives were incorporated as dry powder before water was added to obtain a total sample weight of $25.0 \mathrm{~g}$. The suspensions were equilibrated for $2 \mathrm{~min}$ at 40 ${ }^{\circ} \mathrm{C}$, heated to $95^{\circ} \mathrm{C}$ in $11 \mathrm{~min}\left(5^{\circ} \mathrm{C} / \mathrm{min}\right)$, and kept at this temperature for $10 \mathrm{~min}$. Afterward, the mixtures were cooled to $40^{\circ} \mathrm{C}$ (cooling rate $5{ }^{\circ} \mathrm{C} /$ $\mathrm{min}$ ), and this temperature was held for either 20 or 266 min (until a constant viscosity was obtained). The rotor speed was $160 \mathrm{rpm}$ and viscosity was expressed in $\mathrm{mPa} \cdot \mathrm{s}$, with variations smaller than $20 \mathrm{mPa} \cdot \mathrm{s}$ $(<1.0 \%)$ for identical samples.

Determination of the Resistant Starch Content. The level of RS present in a starch gel was determined based on Åkerberg et al. (35), with some minor modifications. The sample was prepared by heating wheat starch $(10.0 \% \mathrm{dm})$ with or without $1.0 \%$ (dry powder) GMS or $5.0 \%$ defatted amylose-lipid complexes (on starch $\mathrm{dm}$ base) for $20 \mathrm{~min}$ at $100{ }^{\circ} \mathrm{C}$, and afterward cooling it on ice for $30 \mathrm{~min}$. Immediately after the cooling phase, the gel was divided at room temperature into pieces containing approximately $1.0 \mathrm{~g}$ of starch (and placed on a spoon). Each of six subjects, who had not eaten $2 \mathrm{~h}$ before the test and who had brushed their teeth, chewed one sample 15 times (during $15 \mathrm{~s}$ ), before spitting it into a beaker containing $5.0 \mathrm{~mL}$ of water and $1.0 \mathrm{~mL}$ of a pepsin solution $(4.32 \mathrm{mg} /$ $\mathrm{mL}$ deionized water, $3260 \mathrm{EU} / \mathrm{mg}$ pepsin). The samples were adjusted to $\mathrm{pH} 1.5$ with $1.0 \mathrm{M} \mathrm{HCl}$ and then incubated for $30 \mathrm{~min}$ at $37^{\circ} \mathrm{C}$ with stirring at 10 and $20 \mathrm{~min}$. After addition of $10.0 \mathrm{~mL}$ sodium acetate buffer ( $\mathrm{pH} 5.0$, $0.5 \mathrm{M}$ ), the sample was brought to $\mathrm{pH} 5.0$ with $1.0 \mathrm{M} \mathrm{NaOH}$. To these mixtures, $0.125 \mathrm{~mL}$ of a solution containing $\mathrm{CaCl}_{2}(0.30 \mathrm{M})$ and $\mathrm{MgCl}_{2}$ $(0.06 \mathrm{M}), 0.100 \mathrm{~mL}$ isopropanol, $0.125 \mathrm{~mL}$ of pancreatin solution (USPx3, 


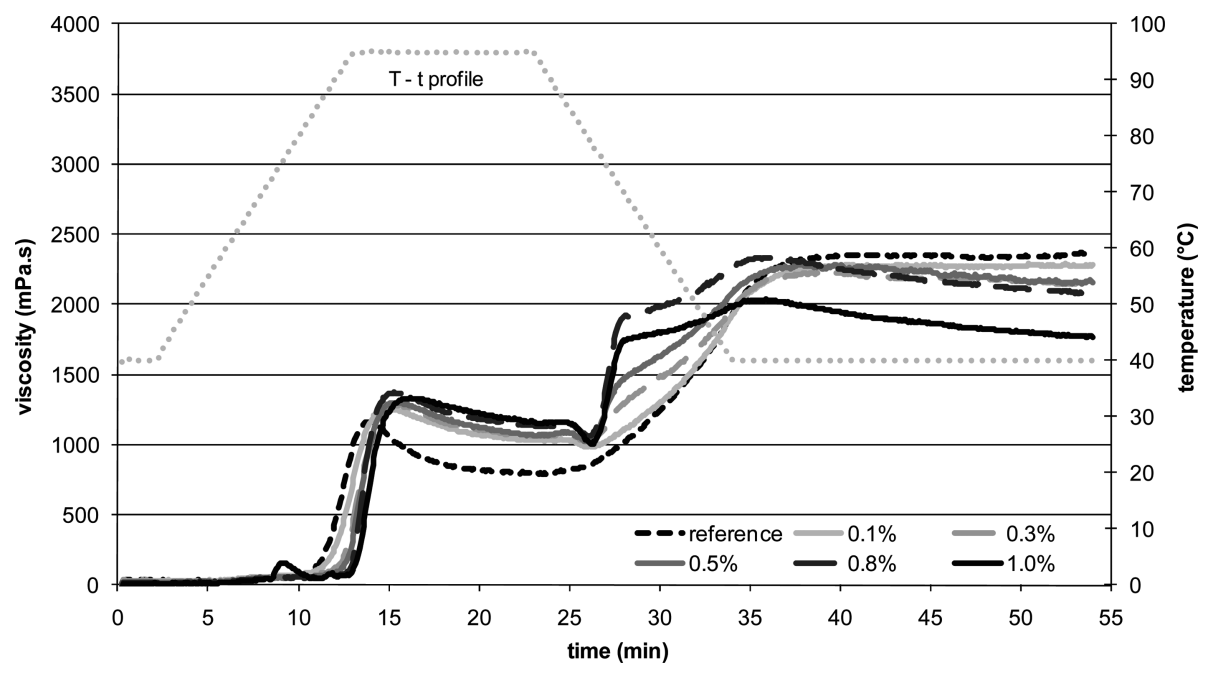

Figure 1. Impact of different concentrations of glycerol monostearate (GMS) on pasting and gelation of starch ( $8.0 \% \mathrm{dm})$.

$106.4 \mathrm{mg} / \mathrm{mL})$ and $0.400 \mathrm{~mL}$ of amyloglucosidase solution $(140 \mathrm{EU} / \mathrm{ml})$ were added. The samples were diluted to a final volume of $50 \mathrm{~mL}$. After $16 \mathrm{~h}$ incubation at $37{ }^{\circ} \mathrm{C}$ with constant stirring $(110 \mathrm{rpm}), 200 \mathrm{~mL}$ of denatured ethanol $\left(97 \%, 60^{\circ} \mathrm{C}\right)$ was added. The polysaccharides were allowed to precipitate during $60 \mathrm{~min}$ and removed by filtration in a Fibertec apparatus (Tecator, Hogänäs, Sweden) using P2 crucibles containing $0.50 \mathrm{~g}$ of Celite. The residues were subsequently washed in the crucibles with aliquots of $78 \%, 97 \%$, and $100 \%$ ethanol. The filtrates were collected and their glucose contents were determined by the GOPOD assay to obtain the potentially available (and thus nonresistant) starch fraction $(=\mathrm{AS})$ of the sample. The filtered residues, on the other hand, were dried overnight at $105^{\circ} \mathrm{C}$. Their total starch, or for that matter, RS contents were determined according to Siljeström et al. (36). They were thus solubilized for $30 \mathrm{~min}$ with $2.0 \mathrm{M} \mathrm{KOH}$ at room temperature, neutralized to pH 6.0 with $5.0 \mathrm{M} \mathrm{HCl}$, incubated for $20 \mathrm{~min}$ at $100^{\circ} \mathrm{C}$ with $100 \mu \mathrm{L}$ of Termamyl $120 \mathrm{~L}$ after, and for $30 \mathrm{~min}$ at $60^{\circ} \mathrm{C}$ and pH 6.0 with $50 \mu \mathrm{L}$ of amyloglucosidase solution (140 EU/mL). The glucose in the sample was again quantified using the GOPOD assay. The glucose concentration was multiplied by 0.9 (to convert glucose into starch) and dilutions were taken into consideration to obtain the percentage of the initial total starch ending up in the residue on the filter (= RS). This amount was subsequently expressed as RS/(RS + AS)*100.

The RS content was measured as the average of (at least) six measurements.

Determination of Hydrolysis Index. The in vitro chewing method described by Granfeldt et al. (29), with some small modifications, was used to determine the rate of in vitro starch degradation of $4.0 \%$ starch dispersions (with and without $1.0 \%$ GMS or $5.0 \%$ defatted amylose-lipid complexes, on starch $\mathrm{dm}$ base). The starch suspensions were prepared by mixing and heating $0.5 \mathrm{~g} \mathrm{dm}$ starch in $12.5 \mathrm{~mL}$ of $0.022 \mathrm{M}$ sodiumpotassium phosphate buffer $[\mathrm{pH} 6.9$, containing $0.4 \mathrm{~g} / \mathrm{L}$ sodium chloride, further referred to as phosphate buffer (29)] for $20 \mathrm{~min}$ at $100{ }^{\circ} \mathrm{C}$ (with stirring every $5 \mathrm{~min}$ ) and subsequent cooling at room temperature for $30 \mathrm{~min}$, with continuous stirring. Each of the six subjects chewed 15 glass beads 15 times (during approximately $15 \mathrm{~s}$ ), expectorated the glass beads into a sieve on top of the beaker containing the starch dispersion, immediately after it was cooled, and $1.0 \mathrm{~mL}$ of pepsin solution $(14000$ $\mathrm{EU} / \mathrm{mL}$ phosphate buffer). The beads were rinsed with the same buffer to collect all the saliva in the beaker. The subjects rinsed their mouths with 5.0 $\mathrm{mL}$ of phosphate buffer for $60 \mathrm{~s}$ and also spat the rinse into the beaker. The samples were then incubated at $37^{\circ} \mathrm{C}$ at $\mathrm{pH} 1.5$ for $30 \mathrm{~min}$. The $\mathrm{pH}$ was adjusted to 6.9 with $2.0 \mathrm{M} \mathrm{NaOH}$ and $1.0 \mathrm{~mL}$ of a pancreatic $\alpha$-amylase solution (containing $1100 \mathrm{EU}$ in $10.0 \mathrm{~mL}$ phosphate buffer) was added. Before the sample was transferred to a dialysis tube $(13 \mathrm{~cm}$; Spectra Por. No. 2, molecular weight cutoff, MWCO, 12-14000), the volume was adjusted to $30 \mathrm{~mL}$ with phosphate buffer. Each tube was incubated in 800 $\mathrm{mL}$ of phosphate buffer (under continuous stirring, $110 \mathrm{rpm}$ ) at $37^{\circ} \mathrm{C}$ for $3 \mathrm{~h}$. Every $30 \mathrm{~min}$, aliquots of the dialysate were withdrawn to determine their reducing sugar contents with the 3,5-dinitro salicylic acid (DNS) method (37). The HI of the total starch of the starch suspension was calculated as the area under the plot of hydrolyzed starch $(\%)$ as a function of time for the sample with additive, divided by the area under the plot for the reference sample (without additive), chewed by the same person. Results are averages of the HI of (at least) six individuals.

Statistical Analyses. The Statistical Analysis System software 8.1 (SAS Institute, Cary, NC, USA) was used for statistical analyses. Results were evaluated using the $t$ test (PROC ANOVA) with a significance level $P<0.05$.

\section{RESULTS AND DISCUSSION}

Rheological Properties of Starch Suspensions with Different Additives. To study the structural features and properties of starch systems with different additives (GMS, SES-AMLCI, and SES-AMLCII), each of them was added in increasing concentrations to a starch suspension $(8.0 \% \mathrm{dm})$. During cooling of the starch reference paste, viscosity increased due to network formation $(38-40)$. This viscosity remained constant during the final holding phase at $40{ }^{\circ} \mathrm{C}$. Figure 1 shows that increasing concentrations of GMS increasingly postponed pasting and decreased breakdown of the starch paste. During cooling of the suspensions, strong increases in viscosity were observed around $70^{\circ} \mathrm{C}$, but, in the final holding phase, viscosities were lower than for the control.

We assume that GMS adsorbs at the starch granule surface, thus impeding water absorption, and, as a consequence, also the observed pasting. Addition of an amylose complexing lipid decreased breakdown, as also noted by others $(7,41,42)$.

The sudden viscosity increase at $70^{\circ} \mathrm{C}$ in the cooling phase was probably due to complexation of GMS with amylose. Osman and Dix (7) earlier stated that, in the presence of surface-active additives, a viscosity increase is observed around $70{ }^{\circ} \mathrm{C}$ for nonwaxy starches. Conde-Petit and Escher (43) suggested that in situ formed amylose-lipid complexes act as junction zones in a network between granules, and thus induce gelation. In this way, these complexes can be regarded as physical cross-links, as suggested earlier by Biliaderis and Tonogai (44) for the increase in elasticity in more concentrated starch gels brought about by lipid additives. Hence, during the cooling phase, the viscosity increase would be higher than for the control, as seen in Figure 1.

Moreover, it may be that, upon addition of a high concentration of free lipids, that is, above the lipid's critical micelle concentration, not all lipid molecules interact with amylose. In principle, these can interact with one another and form aggregates which affect the observed viscosity changes (45). 


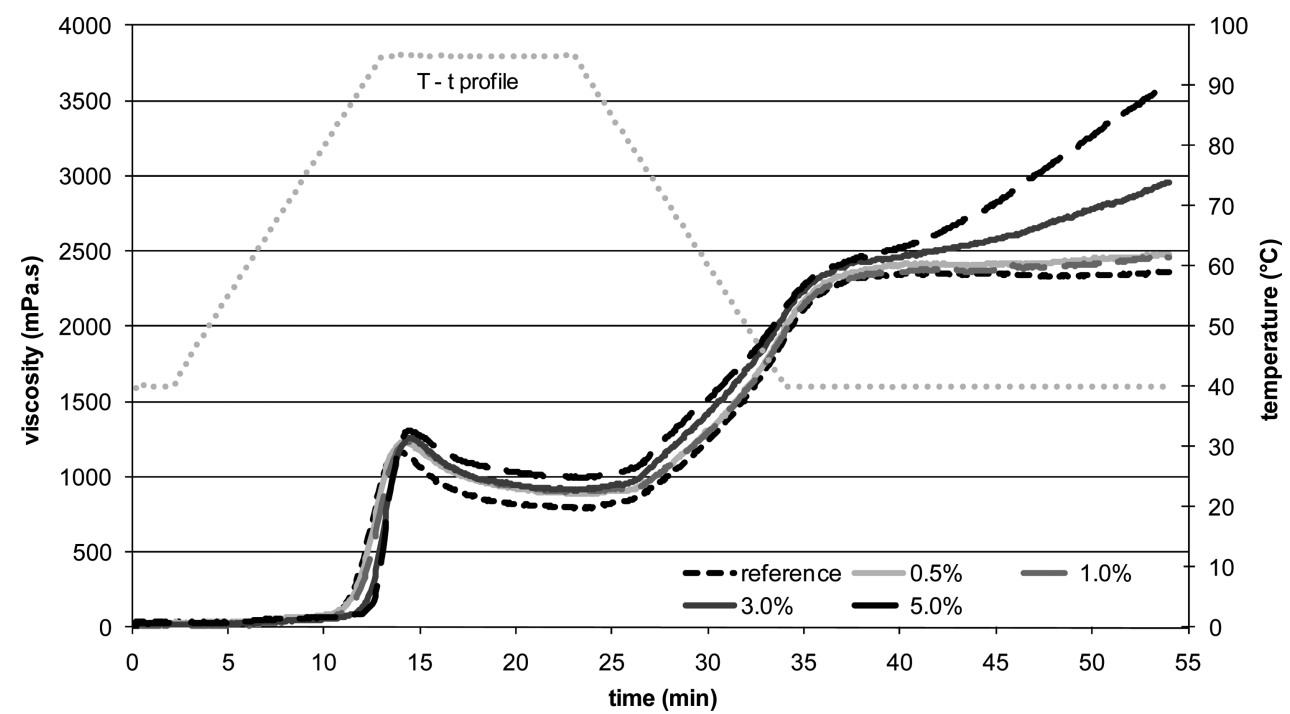

Figure 2. Impact of different concentrations of semienzymically synthesized amorphous amylose-lipid complexes type I (SES-AMLCl) on pasting and gelation of starch $(8.0 \% \mathrm{dm})$.

A decrease in viscosity was observed during the last phase upon addition of GMS to the starch suspension. The presence of this emulsifier results in a network that is less shear resistant than the control. The rivalry between, on the one hand, amylose-amylose interaction (resulting in crystallized amylose) and, on the other hand, amylose-lipid complexation has already been mentioned in the literature on the effect of emulsifiers on gel strength $(4,7,46,47)$. The crystalline amylose structure contributes to network formation, and thus to gel firmness and strength (39). The lower end viscosities at higher lipid concentrations (GMS > 0.1\%) thus indicate a weaker network and less structure even if, in the early cooling phase, amylose-lipid complexes had contributed to structure formation. Because of the lipid layer surrounding the granules, less amylose could be leached. Moreover, as the leached amylose chains are involved in complex formation with the added emulsifier, only a smaller amylose fraction can form amylose double helices during starch gelation $(15,48)$, and network formation occurs to a lesser extent than in the absence of emulsifier.

Figure 2 shows the impact of increasing concentrations of SESAMLCI on the RVA profile. Only minor effects of the additive were observed in the first parts of the curve. Pasting was slightly delayed and breakdown decreased, but to a lesser extent than in the case of addition of pure GMS. At the final holding phase, viscosity of the starch suspensions increased drastically with increasing concentrations of SES-AMLCI. When adding CSAMLC60 to the starch sample, this effect was not seen (data not shown).

During heating, especially at the $95{ }^{\circ} \mathrm{C}$ holding phase, the complexes probably dissociate and set the lipid free, as reported earlier (24). From this point onward, the ligand can impact rheological properties, leading to a small, but still perceivable, change in the initial heating phase. Evidently, the liberation of GMS does not induce a viscosity increase comparable to that observed during the cooling phase upon addition of noncomplexed GMS. The reasons for this observation remain unclear to us.

During the final holding phase, viscosity of the starch suspensions increases strongly with the concentration of amylose-lipid complexes. Apart from the lipid, also the short amylose chains are released in a controlled way. It may be that these small mobile chains form double helices with amylose leached from the starch granules $(49,50)$. This might trigger the double helix formation in the amylose fraction upon cooling, which then would contribute to network structure, and final viscosity. Gidley et al. (51) already mentioned that chains with a degree of polymerization around or lower than 100 can form double helices very well. That this is not seen with CS-AMLC60 emphasizes the importance of the chain length of the amylose involved in the complex.

The viscosity of the starch samples, prepared in the presence of SES-AMLCII, was consistently higher than and parallel throughout the RVA-run with that of the reference (Figure 3). When adding CS-AMLC90, similar parallel profiles were obtained (data not shown). However, the difference with the reference sample was less pronounced, resulting in lower viscosities than in the presence of SES-AMLCII.

The impact of SES-AMLCII can presumably be reduced to that of the addition of inert mass. Their dissociation temperatures $\left(>100{ }^{\circ} \mathrm{C}\right.$ ) are not reached under the conditions used for RVA. We suggest that the complexes, thus, do not interact with starch.

In contrast to what was done in the above time-temperature profile, the final holding phase was extended (to $210 \mathrm{~min}$ ) such that a stable viscosity was obtained for every starch suspension (data not shown). For the reference and the samples to which GMS and SES-AMLCII had been added, the viscosity remained rather unchanged. The sample containing additional SES-AML$\mathrm{CI}$, on the other hand, decreased in viscosity after the initial higher viscosity. It, thus, seemed that the network strength brought about by the liberated short amylose chains is lost under long periods of shear.

Within the context of our work, we can, thus, envisage two ways to strengthen a starch network by use of amylose-lipid complexes. Both in situ formed amylose-lipid complexes as well as short amylose chains can induce network formation during cooling of a heated starch suspension. However, the formed networks vary in strength. In our view, the complexation of the (liberated) lipids with longer leached amylose chains induces gelation without actually strengthening the final network further. This was observed in the GMS supplemented starch-water systems as an initial strong viscosity increase during cooling, followed by a decreased viscosity during the final holding phase.

The short amylose chains released during the RVA run after addition of SES-AMLCI, however, presumably participate in 


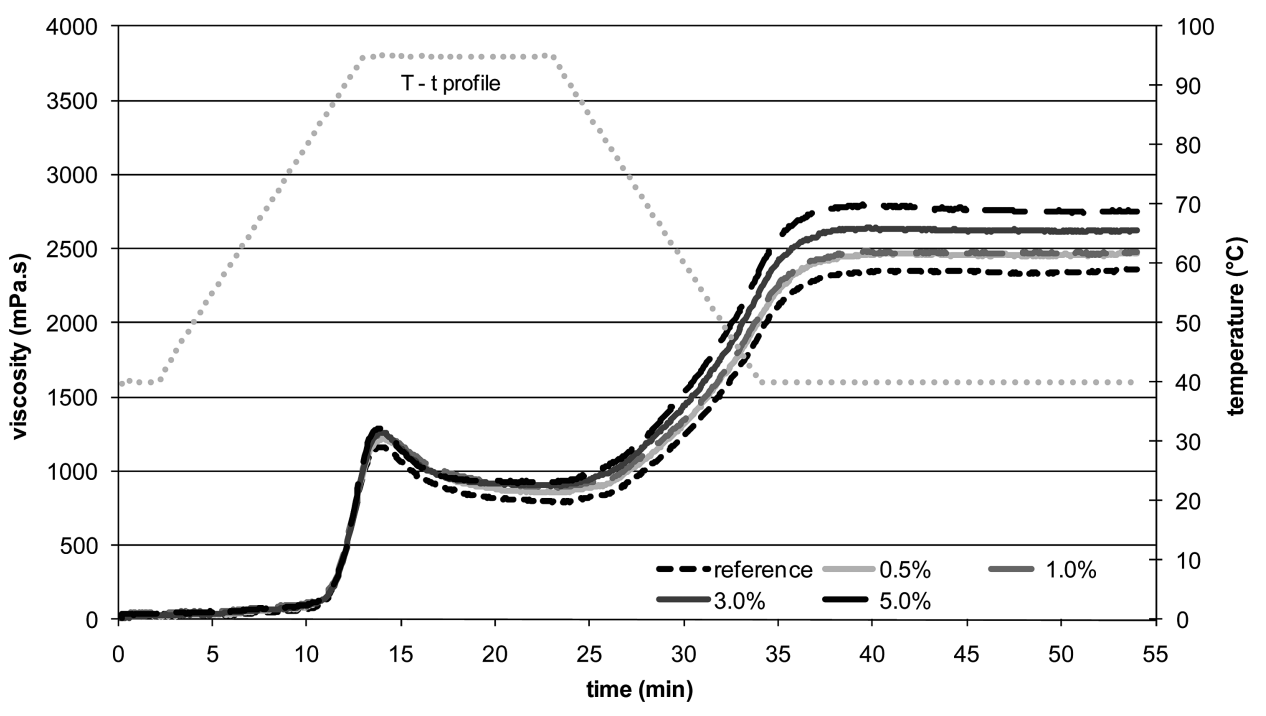

Figure 3. Impact of different concentrations of semienzymically synthesized semicrystalline amylose-lipid complexes type II (SES-AMLCII) on pasting and gelation of starch $(8.0 \% \mathrm{dm})$.

network formation, resulting in high viscosities. However, in the case of short amylose chains, short double helices may be formed with stabilizing forces that are too weak to withstand the shear forces of the RVA paddle. This is reflected in the strong viscosity decrease in the second part of the final holding phase.

However, further research is still needed, for example, rheometry to verify the role of storage and loss moduli, and X-ray diffraction measurements to identify possible differences in the network forming structures upon gelation of starch suspensions with additional amylose-lipid complexes.

In Vitro Enzyme Degradability of Starch Gels (RS and HI). A significant difference in RS content was found between the reference gel, the one containing 1.0\% GMS and those with either SES-AMLCI or SES-AMLCII (Table 1). The hydrolysis index (HIs, Table 1) of starch suspensions with different additives did not differ significantly from that of the reference sample. However, a trend toward higher degradability for samples with an additional 1.0\% GMS and slightly lower degradabilities for those supplemented with $5.0 \%$ SES-AMLCI or SES-AMLCII could be observed. The HIs were significantly negatively correlated with the RS contents of the starch samples $\left(R^{2}=0.95 ; P<\right.$ $0.05)$. This has already been reported following addition of glycerol monopalmitate to potato starch (22). Moreover, lower HIs were only obtained for monodisperse semienzymically synthesized amylose-lipid complexes. When preparing the inclusion complexes in the classical way, higher degradabilities (HI $>105 \%$ ) were obtained for both the amorphous CS-AMLC60 as well as the semicrystalline CS-AMLC90 (data not shown).

The reduction in levels of amylose double helices in the presence of added GMS is reflected in the lower RS content of this gel. RS3, predominantly crystalline amylose, decreased at the expense of amylose-lipid complexation. Szczodrak and Pomeranz (15) ascribed this effect to competition between amylose double helix formation and amylose single helix formation for complexation of the lipid.

Amylose-lipid complexes increased the RS content of the starch gel they were added to. SES-AMLCI addition resulted in higher RS levels. This could be attributed to higher RS3 levels resulting from the contribution of amylose chains freed from the complexes upon dissociation, as also observed in the increased end viscosity of the RVA experiments. SES-AMLCII evidently did not contribute to the amylose network during gelation of
Table 1. Resistant Starch (RS) Content and Hydrolysis Index (HI) of Starch Gels with Different Additives [i.e., Glycerol Monostearate (GMS), SemiEnzymically Synthesized Amorphous Amylose-Lipid Complexes Type I (SES-AMLCl) and Semi-Enzymically Synthesized Semi-Crystalline AmyloseLipid Complexes Type II (SES-AMLCII)], with Standard Deviations between Brackets $^{a}$

\begin{tabular}{lll}
\hline & \multicolumn{1}{c}{$\mathrm{RS}(\%)$} & \multicolumn{1}{c}{$\mathrm{HI}(\%)$} \\
\hline reference $(R)$ & $6.32(0.75) \mathrm{b}$ & $100.0 \mathrm{a}$ \\
$R+1.0 \%$ GMS & $3.26(0.25) \mathrm{a}$ & $112.7(28.1) \mathrm{a}$ \\
$R+5.0 \%$ SES-AMLCI & $7.25(0.85) \mathrm{c}$ & $99.0(17.0) \mathrm{a}$ \\
$R+5.0 \%$ SES-AMLCII & $8.30(0.96) \mathrm{d}$ & $96.3(9.0) \mathrm{a}$ \\
\hline
\end{tabular}

${ }^{a}$ Results are averages of those of at least six subjects. a, b, c, d: Tukey groups for RS and $\mathrm{HI}$ with $P$-value $<0.05$

starch (cfr. supra), but these semicrystalline complexes themselves are hardly degraded and can, as such, be considered as an integral part of the RS fraction.

Observations of amylose-lipid complexes, but not as additives in starch-containing systems, have been made by others $(14,21,22)$. Holm et al. (21), for example, investigated both in vitro and in vivo hydrolysis of amylose-lipid complexes. Lipid complexed amylose was substantially less prone to in vitro hydrolysis than noncomplexed amylose. In vivo, however, amylose-lipid complexes were fully degraded, but at a slower pace than amorphous amylose. However, in the cited articles, amylose-lipid complexes were hydrolyzed as such, and not as additives in starch systems. Amylose-lipid complexes, especially the semicrystalline type II complexes, have already been mentioned as possible part of RS $(22,52)$. The present research confirms this, as seen in the higher RS content and the lower HI.

As the correlation indicates, $\mathrm{HI}$ is strongly related to the RS contents of the different starch gels. This was to be expected. The more RS present in a food system, the slower its hydrolysis since it escapes enzyme degradation.

In conclusion, it can be stated that network strengths correlated well with the in vitro degradability of the tested samples. When $1.0 \%$ GMS was added to starch, RS content decreased significantly and HI increased. For added semienzymically synthesized amylose-lipid complexes, higher RS contents and lower HI were obtained. This indicates that these monodisperse complexes may well contribute to the RS fraction through the 
release of short amylose chains or incorporation of inert, nondegradable material for SES-AMLCI and SES-AMLCII, respectively. This was also reflected in their lower HI.

The controlled release of the complexed ligand and especially the short amylose chains of SES-AMLCI are probably the main contributors to the effects in both rheology and in vitro degradability discussed in this article. Amylose-lipid complexes can thus be used as a tool for changing rheological characteristics and lower the degradability of starch systems.

\section{ABBREVIATIONS USED}

GMS: glycerol monostearate; RS: resistant starch; HI: hydrolysis index; glc-1-P: glucose-1-phosphate; GOPOD: glucose oxidase - peroxidase; EU: enzyme units; DP: degree of polymerization; SES-AMLC: semienzymically synthesized amylose-lipid complexes; CS-AMLC: classically synthesized amylose-lipid complexes; DSC: differential scanning calorimetry; $T_{\mathrm{O}}$ : onset temperature; $T_{\mathrm{p}}$ : peak temperature; $T_{\mathrm{c}}$ : conclusion temperature; $\Delta H$ : dissociation enthalpy; RVA: rapid visco analyzer.

\section{ACKNOWLEDGMENT}

The authors wish to acknowledge Liza Rosén and Lisbeth Persson from the Division of Applied Nutrition and Food Chemistry, Lund University (Sweden) for demonstrating the RS and HI analysis methods.

\section{LITERATURE CITED}

(1) Krog, N. Theoretical aspects of surfactants in relation to their use in breadmaking. Cereal Chem. 1981, 58 (3), 158-164.

(2) Kulp, K.; Ponte, J. G. Staling of white pan bread - Fundamental causes. Crit. Rev. Food Sci. Nutr. 1981, 15 (1), 1-48.

(3) Gomez, M.; del Real, S.; Rosell, C. M.; Ronda, F.; Blanco, C. A.; Caballero, P. A. Functionality of different emulsifiers on the performance of breadmaking and wheat bread quality. Eur. Food Res. Technol. 2004, 219 (2), 145-150.

(4) Hoover, R.; Hadziyev, D. Characterization of potato starch and its monoglyceride complexes. Starch-Stärke 1981, 33 (9), 290-300.

(5) Pisesookbunterng, W.; D’Appolonia, B. L. Bread staling studies. 1. Effect of surfactants on moisture migration from crumb to crust and firmness values of bread crumb. Cereal Chem. 1983, 60 (4), 298-300.

(6) Krog, N. Influence of food emulsifiers on pasting temperature and viscosity of various starches. Starch-Stärke 1973, 25 (1), 22-27.

(7) Osman, E. M.; Dix, M. R. Effects of fats and nonionic surface-active agents on starch pastes. Cereal Chem. 1960, 37 (4), 464-475.

(8) Eliasson, A. C.; Carlson, T. L. G.; Larsson, K.; Miezis, Y. Some effects of starch lipids on the thermal and rheological properties of wheat starch. Starch-Stärke 1981, 33 (4), 130-134.

(9) Mikus, F. F.; Hixon, R. M.; Rundle, R. E. The complexes of fatty acids with amylose. J. Am. Chem. Soc. 1946, 68, 1115-1123.

(10) Eliasson, A. C. Starch gelatinization in the presence of emulsifiers - A morphological study of wheat starch. Starch-Stärke 1985, 37, 411-415.

(11) Lindqvist, I. Cold gelatinization of starch. Starch-Stärke 1979, 31 (6), 195-200.

(12) Ghiasi, K.; Varriano-Marston, E.; Hoseney, R. C. Gelatinization of wheat starch. 2. Starch-surfactant interaction. Cereal Chem. 1982, 59 (2), 86-88.

(13) Keetels, C. J. A. M.; vanVliet, T.; Jurgens, A.; Walstra, P. Effects of lipid surfactants on the structure and mechanics of concentrated starch gels and starch bread. J. Cereal Sci. 1996, 24 (1), 33-45.

(14) Czuchajowska, Z.; Sievert, D.; Pomeranz, Y. Enzyme-resistant starch. 4. Effects of complexing lipids. Cereal Chem. 1991, 68 (5), $537-542$.

(15) Szczodrak, J.; Pomeranz, Y. Starch-lipid interactions and formation of resistant starch in high-amylose barley. Cereal Chem. 1992, 69 (6), 626-632.

(16) Berry, C. S. Resistant starch - Formation and measurement of starch that survives exhaustive digestion with amylolytic enzymes during the determination of dietary fiber. J. Cereal Sci. 1986, 4 (4), 301-314.
(17) Gee, J. M.; Johnson, I. T.; Lund, E. K. Physiological properties of resistant starch. Eur. J. Clin. Nutr. 1992, 46, S125-S125.

(18) Englyst, H. N.; Kingman, S. M.; Cummings, J. H. Classification and measurement of nutritionally important starch fractions. Eur. J. Clin. Nutr. 1992, 46, S33-S50.

(19) Eerlingen, R. C.; Delcour, J. A. Formation, analysis, structure and properties of type-III enzyme resistant starch. J. Cereal Sci. 1995, 22 (2), 129-138.

(20) Sajilata, M. G.; Singhal, R. S.; Kulkarni, P. R. Resistant starch - A review. Compr. Rev. Food Sci. Food Saf. 2006, 5 (1), 1-17.

(21) Holm, J.; Björck, I.; Ostrowska, S.; Eliasson, A. C.; Asp, N. G.; Larsson, K.; Lundquist, I. Digestibility of amylose-lipid complexes invitro and invivo. Starch-Stärke 1983, 35 (9), 294-297.

(22) Tufvesson, F.; Skrabanja, V.; Björck, I.; Elmstahl, H. L.; Eliasson, A. C. Digestibility of starch systems containing amylose-glycerol monopalmitin complexes. Food Sci. Technol. 2001, 34 (3), 131-139.

(23) Gudmundsson, M. Effects of an added inclusion-amylose complex on the retrogradation of some starches and amylopectin. Carbohydr. Polym. 1992, 17 (4), 299-304.

(24) Gelders, G. G.; Goesaert, H.; Delcour, J. A. Amylose-lipid complexes as controlled lipid release agents during starch gelatinization and pasting. J. Agric. Food Chem. 2006, 54 (4), 1493-1499.

(25) Gelders, G. G.; Goesaert, H.; Delcour, J. A. Potato phosphorylase catalyzed synthesis of amylose-lipid complexes. Biomacromolecules 2005, 6 (5), 2622-2629.

(26) Biliaderis, C. G.; Page, C. M.; Slade, L.; Sirett, R. R. Thermalbehavior of amylose-lipid complexes. Carbohydr. Polym. 1985, 5 (5), 367-389.

(27) Galloway, G. I.; Biliaderis, C. G.; Stanley, D. W. Properties and structure of amylose-glyceryl monostearate complexes formed in solution or on extrusion of wheat-flour. J. Food Sci. 1989, 54 (4), 950-957.

(28) Gelders, G. G.; Vanderstukken, T. C.; Goesaert, H.; Delcour, J. A. Amylose-lipid complexation: a new fractionation method. Carbohydr. Polym. 2004, 56 (4), 447-458.

(29) Granfeldt, Y.; Björck, I.; Drews, A.; Tovar, J. An invitro procedure based on chewing to predict metabolic response to starch in cereal and legume products. Eur. J. Clin. Nutr. 1992, 46 (9), 649-660.

(30) Roger, P.; Axelos, M. A. V.; Colonna, P. SEC-MALLS and SANS studies applied to solution behavior of linear $\alpha$-glucans. Macromolecules 2000, 33 (7), 2446-2455.

(31) Saheki, S.; Takeda, A.; Shimazu, T. Assay of inorganic-phosphate in the mild $\mathrm{pH}$ range, suitable for measurement of glycogen-phosphorylase activity. Anal. Biochem. 1985, 148 (2), 277-281.

(32) Dubois, M.; Gilles, K. A.; Hamilton, J. K.; Rebers, P. A.; Smith, F. Colorimetric method for determination of sugars and related substances. Anal. Chem. 1956, 28, 350-356.

(33) Nelson, N. A photometric adaptation of the Somogyi method for the determination of glucose. J. Biol. Chem. 1944, 153, 375-380.

(34) Somogyi, M. A new reagent for the determination of sugars. J. Biol. Chem. 1945, 61-68.

(35) Akerberg, A. K. E.; Liljeberg, H. G. M.; Granfeldt, Y. E.; Drews, A. W.; Björck, I. M. E. An in vitro method, based on chewing, to predict resistant starch content in foods allows parallel determination of potentially available starch and dietary fiber. J. Nutr. 1998, 128 (3), 651-660.

(36) Siljestrom, M.; Björck, I.; Eliasson, A. C.; Lonner, C.; Nyman, M.; Asp, N. G. Effects on polysaccharides during baking and storage of bread - In vitro and in vivo studies. Cereal Chem. 1988, 65 (1), 1-8.

(37) Hostettler, F.; Borel, E.; Deuel, H. Über die reduktion der 3,5dinitrosalicylsäure durch zucker. Helv. Chim. Acta 1951, 34, 2132-2139.

(38) Zeng, M.; Morris, C. F.; Batey, I. L.; Wrigley, C. W. Sources of variation for starch gelatinization, pasting, and gelation properties in wheat. Cereal Chem. 1997, 74 (1), 63-71.

(39) Miles, M. J.; Morris, V. J.; Orford, P. D.; Ring, S. G. The roles of amylose and amylopectin in the gelation and retrogradation of starch. Carbohydr. Res. 1985, 135 (2), 271-281.

(40) Miles, M. J.; Morris, V. J.; Ring, S. G. Gelation of amylose. Carbohydr. Res. 1985, 135 (2), 257-269.

(41) Schoch, T. J. Mechano-chemistry of starch. Wallerstein Commun. 1969, 32, 109. 
(42) Eliasson, A. C.; Larsson, K.; Miezis, Y. On the possibility of modifying the gelatinization properties of starch by lipid surface coating. Starch-Stärke 1981, 33 (7), 231-235.

(43) Conde-Petit, B.; Escher, F. Complexation induced changes of rheological properties of starch systems at different moisture levels. J. Rheol. 1995, 39 (6), 1497-1518.

(44) Biliaderis, C. G.; Tonogai, J. R. Influence of lipids on the thermal and mechanical properties of concentrated starch gels. J. Agric. Food Chem. 1991, 39 (5), 833-840.

(45) Tang, M. C.; Copeland, L. Analysis of complexes between lipids and wheat starch. Carbohydr. Polym. 2007, 67 (1), 80-85.

(46) Mitchell, W. A.; Zillmann, E. The effect of fatty acids on starch and flour viscosity. Trans Am. Assoc. Cereal Chem. 1951, 9, 64-79.

(47) Kaur, L.; Singh, J.; Singh, N. Effect of glycerol monostearate on the physico-chemical, thermal, rheological and noodle making properties of corn and potato starches. Food Hydrocoll. 2005, 19 (5), 839849.

(48) Stampfli, L.; Nersten, B. Emulsifiers in bread making. Food Chem. 1995, 52 (4), 353-360.

(49) Jane, J. L.; Chen, J. F. Effect of amylose molecular size and amylopectin branch chain length on paste properties of starch. Cereal Chem. 1992, 69 (1), 60-65.
(50) Ozcan, S.; Jackson, D. S. The impact of thermal events on amylosefatty acid complexes. Starch-Stärke 2002, 54 (12), 593-602.

(51) Gidley, M. J.; Cooke, D.; Darke, A. H.; Hoffmann, R. A.; Russell, A. L.; Greenwell, P. Molecular order and structure in enzymeresistant retrograded starch. Carbohydr. Polym. 1995, 28 (1), 23-31.

(52) Crowe, T. C.; Seligman, S. A.; Copeland, L. Inhibition of enzymic digestion of amylose by free fatty acids in vitro contributes to resistant starch formation. $J$. Nutr. 2000, 130 (8), 2006-2008.

Received for review October 7, 2009. Revised manuscript received December 10, 2009. Accepted December 10, 2009. This publication is in part financially supported by the European Commission in the Communities sixth Framework Program, Project HEALTHGRAIN (FOOD-CT-2005-514008). It reflects the author's views and the Community is not liable for any use that may be made of the information contained in this publication. This research was also conducted in the framework of research project G.0427.07, financed by the Fund for Scientific Research - Flanders (FWO), Brussels, Belgium, and is part of the Methusalem program "Food for the Future" at the K.U. Leuven. 